Rakenteiden Mekaniikka (Journal of Structural Mechanics)

Vol. 50, No 3, 2017, pp. 318 - 322

https://rakenteidenmekaniikka.journal.fi/index

https://doi.org/10.23998/rm.65050

(c) The author(s) 2017.

Open access under CC BY-SA 4.0 license.

\title{
Counterweight measurements device development
}

\author{
Pasi Halla-aho ${ }^{1}$, Antti Mäntylä, Tero Frondelius, Tommi Helander and Juha Hautala
}

Summary. This article describes the use of a remotely controlled and smart measurement device that is applied in very harsh environments to measure vibrations inside a medium speed internal combustion engine. The developed device is exposed to oil, high temperature and vibration and is able to measure, compute and send the results simultaneously, for example, to a website monitoring tool. The key feature of this device is that the analysis of the results is done inside the device by utilizing signal processing algorithms. The method is very efficient as it enables very long measurement times due to a low power consumption. The smart data analysis makes it easy and fast to utilize the data for product development and trouble shooting.

Key words: Wärtsilä, Nome $\mathrm{Oy}$, accelerometer, vibration measurements

Received 22 June 2017. Accepted 15 August 2017. Published online 21 August $201 \%$.

\section{Introduction}

Long medium speed diesel and gas engine dynamics are described excessively in $[2,5$, 6]. Acceleration measurement inside the medium speed diesel engine trough telemetry equipments were considered time consuming and complicated measurement arrangement, where the preparation of measurement was taking a lot of time and could only be made by specially trained experts. When measurements were requested in ships or power plants around the world, the complexity of the problem increased. All measurement equipment and highly competent persons were required to be transported to the site and engine needs to be stopped for long period of time to prepare the measurement setup. This also ended up to be really expensive. Other engine telemetry measurements are briefly shown in $[1,2,3]$.

New portable measurement device concept were decided to develop in order to decrease the preparation time as well as the data analysis time in-situ conditions. Device should be possible to transport on an airplane quickly to the site. It should be easy to assemble inside the engine without stopping the engine for several days for the preparation. Measurement operation should be robust and easy. The device should be able to operate several days or even weeks in harsh environment exposed to heat, oil and vibration. Measurement data transfer from inside the engine to data server should be reliable. Measurement data should be analyzed simultaneously in-situ to be able to make decision of further measurements

${ }^{1}$ Corresponding author. pasi.halla-aho@wartsila.com 


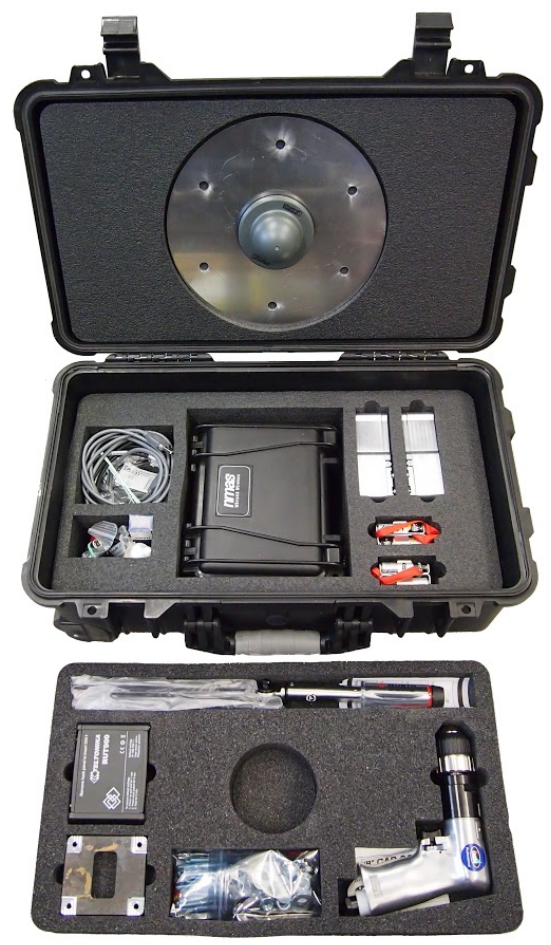

Figure 1. NMAS for Wärtsilä

if needed. Remote control of the measurement settings was required to be able to adapt to variable engine operation conditions without stopping the engine.

\section{Design concept}

Simulation is an essential part of modern product development [4]. Therefore finite element model calculation is performed also for our measurement device. See Figure 2 where both the assembly loads and running condition loads are modeled.
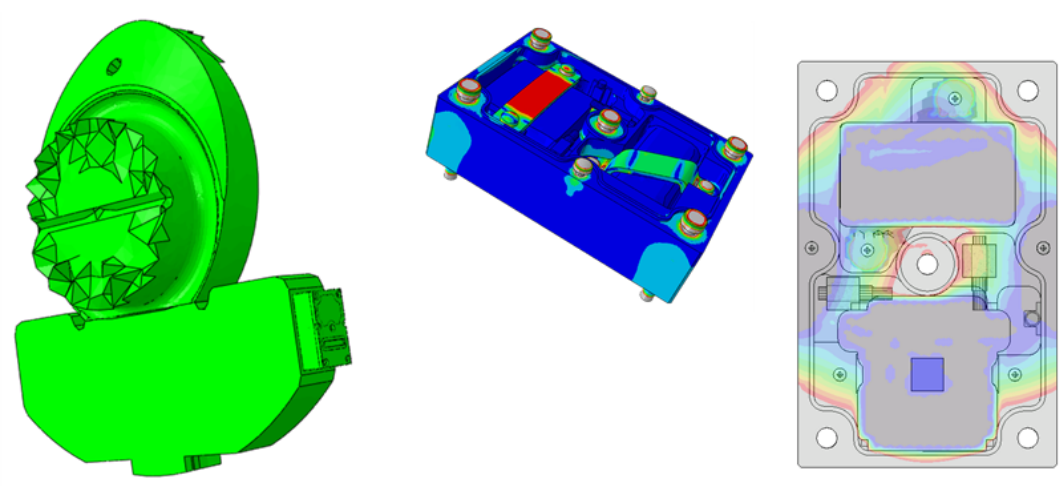

Figure 2. Finite Element Method (FEM) model of the gauge

Due to the changes in characteristic value calculations and the general nmas system remote monitoring possibilities, the unit could be built in a way that its usage requires no 
special training. This idea lead to improvements in the housing and user interface design. Remote assistance could be given via a remote connection.

The whole system with all necessary tools was designed to fit in one carry-on bag for easy transportation. The unit does not include any materials that are considered a risk in airplanes. The carry-on bag design makes it also possible to send the whole package as mail. Main components of the system are a carry-on bag with all components and mounting tools, two sensor units and the measurement device with display see Figure 1.

Using the device is easy. First stage is to prepare the counterweight with tools provided in the carry-on bag. Sensor units are mounted to both sides of the counterweight. Finally all hatches can be closed and engine started. Measurements can be simply started on the device screen.

The user interface was designed to provide simple start-stop operation. The operator should also be able to see immediate feedback of the current measurement status and signal values. Status and values are presented directly on measurement device screen.

\section{Data transfer technology development}

The project target was to develop a measurement device based on the latest technology and for operation in extremely demanding environments. For this reason, the project was divided into smaller phases. All test phases included actual environment testing. The first phase was the selection and testing of available radio technology in the actual environment. High voltage regulators and metal structures are known to cause transfer errors over analog radio transmission. For this reason, a digital radio was selected for data transfer. Digital radios have a great variety of different operating bands and protocols. On the basis of the data rate, reliability and power consumption, a 2,4 $\mathrm{GHz}$ band radio was selected. Simple data transfer tests were carried out on testing facilities to confirm that the radio performs as required.

Wireless live data transmission with embedded radio communication is typically a compromise of power consumption and a data transfer rate. Usually a higher data transfer rate requires higher energy consumption. Vibration measurements typically have a high accuracy and sample rate. For testing the radio performance and to verify the data validity, live measurement data was required from the measurement device. The requirements also included the ability to provide synchronized data from two different measurement locations, both locations having three sensor positions. These requirements resulted in such a high data transfer rate that a special radio communication protocol was implemented. The radio protocol was created to maximize the actual data payload on radio packets with a reasonable power consumption. Tests inside an engine proved that the selected radio with the special protocol could perform synchronized measurements in the desired places on a rotating shaft. However, shaft rotation caused a higher amount of data transfer errors, and therefore the communication protocol had to be improved for live data.

The nmas system has built-in secure remote connection possibilities. The connection can be used to monitor measurement status and signals remotely. The user can view data remotely as soon as it is measured. The connection can also be used for changing measurement parameters after trial runs. The remote connection can be created with any normal mobile phone or $3 \mathrm{G}$ modem and the connection is activated automatically as soon as the public network is accessible. 


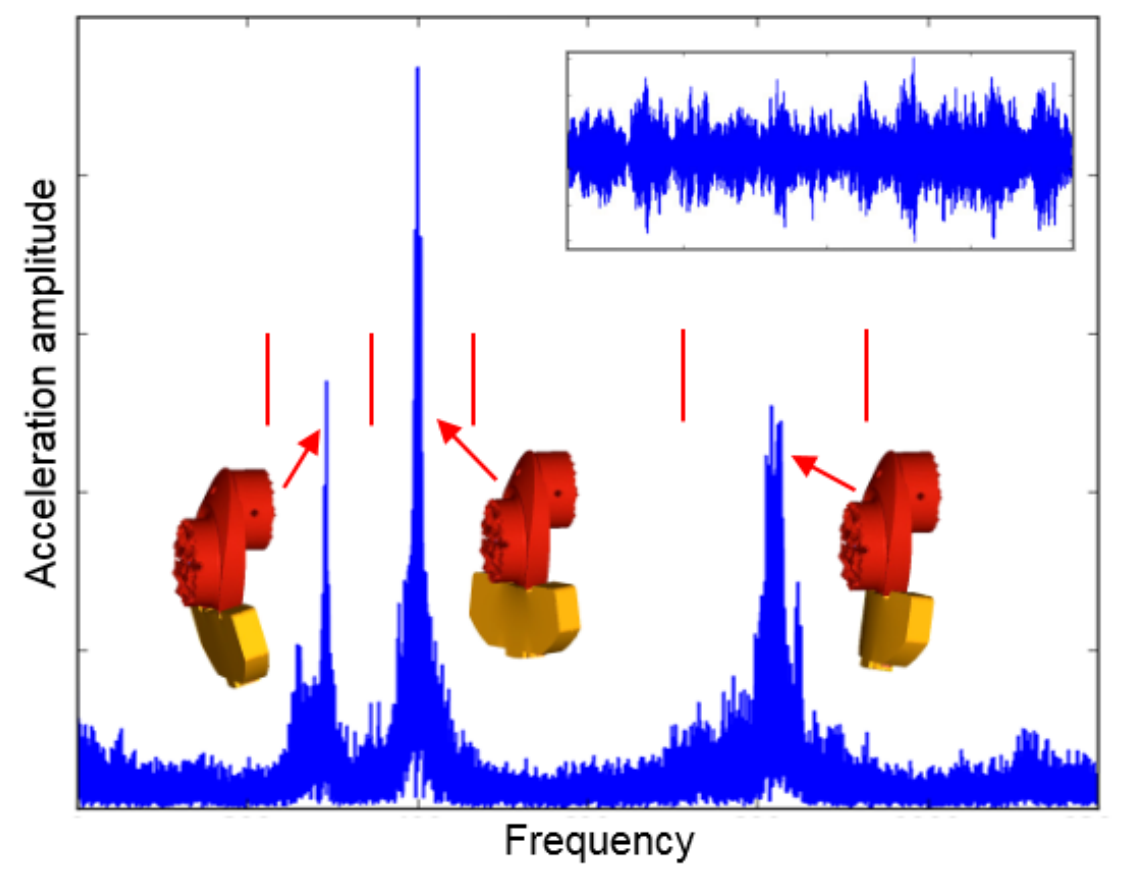

Figure 3. Time signal and FFT-spectrum of the measurement data

\section{Data analysis}

The core feature of the device is the intelligent data post-processing inside the device. The purpose of the measurement is to get the displacement amplitudes of the counterweight for each specific eigenmode. An intelligent algorithm that can perform all needed calculations on the fly has been developed. The algorithm can be triggered automatically according to specified limit values to avoid unnecessary calculations when nothing interesting is happening. The mathematical principle of the algorithm is based on Fast Fourier Transform (FFT) and double integration. The frequency bands for each interesting eigenmode are defined remotely. The FFT of the acceleration signal is done and double integrated to displacement for each frequency band. Time signals of the displacement are then obtained by inverse FFT. Finally, the modal displacement amplitudes are calculated by using a time window and the running amplitude principle.

The time signal and FFT of the measurement data are shown in Figure 3. The algorithm was validated by comparing results from the device and from traditional measurement data analyzed manually in the office. The calculation inside the box reduces amount of data from high frequency time signal to few key numbers per second. Results are available in real time via network. The manual effort of further data analysis is not needed but still possible. The algorithm can be also set to record raw data from interesting events if needed.

\section{Conclusions}

This paper briefly describes the design concept of the Wartsila nmas measurement device fitted in all inclusive carry-on bag. Key message of this paper is the measurement easiness, the goal was to make measurement equipment that all normal mechanics can use and operate, thus saving time and money and multiply the possibilities to perform these 
dedicated measurements all around the world.

Future work will be interesting comparison of the measurements from the different installations around the world. Also copying this concept to other type measurements, which could be performed all around the world, is naturally under investigation.

\section{References}

[1] Jukka Aho and Tero Frondelius. Analyzing 3 TB field measurement data set. Rakenteiden Mekaniikka, 50(3):224-228, 2017. URL https://doi.org/10.23998/rm.64942.

[2] Tero Frondelius, Pasi Halla-aho, and Antti Mäntylä. Crankshaft development with virtual engine modelling. In CIMAC Congress Helsinki, 2016.

[3] Jussi Göös, Anton Leppänen, Antti Mäntylä, and Tero Frondelius. Large bore connecting rod simulations. Rakenteiden Mekaniikka, 50(3):275-278, 2017. URL https://doi.org/10.23998/rm.64658.

[4] Juho Könnö, Hannu Tienhaara, and Tero Frondelius. Wärtsilä digital design platform. Rakenteiden Mekaniikka, 50(3):234-238, 2017. URL https ://doi .org/10.23998/rm. 64621.

[5] Teemu Kuivaniemi, Antti Mäntylä, Ilkka Väisänen, Antti Korpela, and Tero Frondelius. Dynamic gear wheel simulations using multi body dynamics. Rakenteiden Mekaniikka, 50(3):287-291, 2017. URL https://doi.org/10.23998/rm.64944.

[6] Ilkka Väisänen, Antti Mäntylä, Antti Korpela, Teemu Kuivaniemi, and Tero Frondelius. Medium speed engine crankshaft analysis. Rakenteiden Mekaniikka, 50(3): 341-344, 2017. URL https://doi.org/10.23998/rm.64916.

Tommi Helander, Juha Hautala

Nome Oy

Lummintie 9

90460 Oulunsalo

tommi.helander@nome.fi, juha.hautala@nome.fi

Pasi Halla-aho, Antti Mäntylä, Tero Frondelius

Wärtsilä

Järvikatu 2-4

65100 Vaasa

pasi.halla-aho@wartsila.com, antti.mantyla@wartsila.com

tero.frondelius@wartsila.com 